\title{
Cytological Changes During Oogenesis in Exorista sorbillans (Diptera: Tachinidae)
}

\author{
H. P. PUTTARAJU AND H. B. MANJUNATHA
}

Department of Sericulture, Jnana Bharathi, Bangalore University, Bangalore 560 056, India

\begin{abstract}
Ann. Entomol. Soc. Am. 87(6): 891-900 (1994)
ABSTRACT The cytological changes and growth rate of nurse cell nuclei, the oocyte nucleus, and the egg chamber during 14 stages of egg development in $E$. sorbillans Wiedemann are described. Stages $1-3$ are mitotically active, resulting in the formation of one oocyte and 15 nurse cells. The visible nonbanded polytene chromosomes are formed at stage 3 in $32 \mathrm{n}$ nuclei of smaller nurse cells and $64 \mathrm{n}$ nuclei of larger nurse cells. The larger nurse cell nuclei attain a maximal ploidy of $1024 \mathrm{n}$ at stage 10 . Soon after disintegration of the polytene chromosomes, the nurse cells at stage 6 synthesize the nuclear proteins and transfer them to the developing oocyte, which grows rapidly from stages 11 to 13. At stages 13 and 14, the nurse cells disintegrate and the oocyte matures with chorion, aeropyles, operculum, micropyle, and hatching pleat. At the end of stage 14, the matured oocyte has enlarged to $137,651.92$ times that of the oogonium. The results are compared with those from allied species.
\end{abstract}

KEY WORDS Exorista sorbillans, endomitosis, vitellogenesis

Exorista sorbillans Wiedemann is a serious endoparasite of silkworm, Bombyx mori L., and causes considerable damage to the silk industry (Siddappaji \& Channabasavanna 1990). The general morphology of the female reproductive system (Patil \& Govindan 1984), the ovarian chromosomes in adult E. sorbillans (Puttaraju \& Chowdaiah 1984), and reproductive behavior and its potential have been discussed (Siddappaji \& Channabasavanna 1990). Recently, we described the development of the ovary and the structure of the egg of $E$. sorbillans (Manjunatha \& Puttaraju 1992a, 1993). In this article, we extend the earlier work and describe in detail the cytological changes, growth rate, and the sequence of events that occur during 14 stages of egg development.

\section{Materials and Methods}

Postparasitic maggots of $E$. sorbillans were collected from the silkworm cocoon market at Ramanagaram, Karnataka, India, immediately after they had emerged from their host cocoons. The maggots were allowed to become adults in wire-mesh cages. The adults were held in the same cages with cotton balls wetted with $8 \%$ glucose. Female pupae $4 \mathrm{~d}$ old were selected to study ovarian development, because younger pupae have immature ovaries (Manjunatha \& Puttaraju 1992a). The selected healthy pupae were used in batches at 24-h intervals until emergence. Similarly, female flies aged about 4 , $12,24,48,72,96,120$, and $144 \mathrm{~h}$ were also used for this study. The selected pupae and adults were dissected in insect Ringer's solution. The ovaries were removed and fixed in Kahle's fluid. The ovarioles were separated in fresh Kahle's fluid and stained following the modified SchmuckMetz whole-mount technique (Whiting 1950).

The chromosomes were prepared from ovaries by the method of Manjunatha \& Puttaraju (1992b).

The process of oogenesis has been subdivided for convenience into 14 stages by modifying the method of King et al. (1956) for Drosophila melanogaster (Meigen) and Goodman et al. (1968) for Musca domestica L. The nine criteria for idetification were (1) mitotic division of oogonium, (2) size and location of cysts in germarium, (3) cytology of oocyte and nurse cells, (4) degree of endomitosis in nurse cell nuclei, (5) size of oocyte related to nurse cell or to entire egg chamber, (6) rate of vitellogenesis, (7) presence or absence of border cells, (8) height of the follicular epithelium, and (9) degree of development of such structures as the wall which separates the nurse cells from the oocyte, the micropyle, and the dorsal appendages.

The average volumes of egg chambers, oocyte nuclei, and nurse cell nuclei were measured from 25 whole mounts of ovarian tubules at different stages of oogenesis. The ploidy and the DNA content were estimated based on the volume $\left(\pi / 6 w^{2} l\right)$ of the nurse cell nuclei in their respective stages. The DNA content of the nurse cell nuclei was estimated according to the 
method followed by Beattie \& Cheney (1979) in Lucilia cuprina (Wiedemann).

\section{Results}

Of the 14 stages of the development of the primary oocyte (egg chamber) during oogenesis of $E$. sorbillans, stage 1 comprises polar filament and germarial cyst (Fig. 1). The terminal narrow polar filament at the apex of the germarium contains an average of 20 mitotically active germ cells (Fig. 2). Each germarial cell divides into two daughter cells. One of them repeats the same process, and these remain as oogonial stem cells. The other cell is displaced basally and becomes the oogonium, whose volume is about $164.7 \mu^{3}$. The oogonium undergoes four consecutive synchronous mitotic divisions to produce a cyst of 16 daughter cells (cystoblasts). All these 16 daughter cells are connected with one another by intercellular bridges. The resulting sibling cluster is finally packed in one egg chamber at the base of the germarium (Fig. 3). Occasionally, we have observed 32 daughter cells instead of the usual 16 in an egg chamber (Fig. 4). The anterior part of the germarium consists of $\approx 300$ oogonial cells (Figs. 1 and 3). After completion of the mitotic divisions among 16 or 32 daughter cells, one sibling forms an oocyte and the remaining cells become nurse cells enclosed by a few follicular cells; these begin an independent behavior. However, it is difficult to differentiate the oocyte and nurse cells among 16 cystoblast cells which are enveloped in a single layer of follicular cells. A faint line of separation is clearly seen (Fig. 3) between the two cysts located at the posterior end of the germarium. This indicates the formation of the first egg chamber, which measures $\approx 44,832.19 \mu^{3}$ in volume and $42.55 \mu \mathrm{m}$ in length.

At stage 2, the first egg chamber pinches off from the germarium with 16 cystoblasts surrounded by follicular epithelium. At this stage, it is difficult to differentiate the oocyte from the nurse cells in the circular egg chamber (Fig. 5) because of their similar size and volume. In early endomitosis, the nurse cell nuclei stain pale, which helps distinguish the nurse cells (Fig. 6). When the ploidy reaches $32 \mathrm{n}$ the nurse cell nuclei (NCN) attain $2,103.52 \mu^{3}$ in volume. While the oocyte exhibits pachytene (Fig. 7) and diplotene stages, the follicular cells increase in number and change shape from oval to cuboidal (Fig. 8).

A major change takes place in the nurse cells during stage 3 . When the maximal level of ploidy ( $32 n$ in smaller NCN and $64 n$ in larger NCN) is attained, the polytene chromosomes are readily visible as five paired, thicker, meandering threads associated with Feulgen-positive blobs (Figs. 9 and 10). At this stage, because of DNA amplification, the volume of NCN is $2,894.76$ $\mu \mathrm{m}^{3}$. At stage 4 , the first egg chamber changes from circular to oval and also enlarges in almost all follicles (Fig. 11), indicating the beginning of vitellogenesis. The oocyte, smaller than the adjacent nurse cells, is clearly visible (Fig. 12); its size is equal to the average size of the nuclei of the nurse cells. The oocyte and nurse cell cytoplasm show stain difference, i.e., ooplasm is acidophilic, whereas the cytoplasm of nurse cells is basophilic (Figs. 12 and 13).

In stage 5 , the posterior NCN undergo one more duplication of chromosomes and complete the process of endomitosis earlier than the anterior NCN. When $128 \mathrm{n}$ ploidy occurs in these NCN, the polytene nature of the chromosomes begins to disappear. The stranded polytene chromosomes disintegrate into chromatin material, which is evenly distributed in the nurse cell nuclei, increases the volume of NCN to about $3746.35 \mu^{3}$ and appears similar to stage 6 . In the anterior NCN, the process of endomitosis is yet to be completed, because their nuclei contain stranded polytene chromosomes resembling stage 4 . Further, there is variation in size among the 15 NCN present in the egg chamber; four are large $\left(51,786.787 \mu \mathrm{m}^{3}\right)$, seven are intermediate $\left(24,288.644 \mu^{3}\right)$, and four are small $(14,661.671$ $\left.\mu \mathrm{m}^{3}\right)$. During stage 6 , there is an increase in size of the 15 nurse cells and the oocyte coupled with increased size of the follicle (Table 1; Fig. 14). In this stage, the process of endomitosis is completed in all 15 NCN. When chromosomal replication stops, the polytene chromosomes disintegrate in all the nurse cell nuclei (Figs. 12 and 13). The size of the oocyte increase further with the presence of the characteristic Feulgen-positive karyosome at the anterior peripheral region and Feulgen-negative plasmosome at the lower peripheral region (Fig. 13). The size of the follicular cells remains the same but the number increases.

During stage 7 , the egg chamber increases again in length and volume (see Table 1) and becomes elliptical. The height of the follicular epithelial cells above the oocyte increases. The yolk material occupies about one-fourth of the egg chamber during stage 8 , and the oocyte nucleus is pushed laterally from its posterior position (Fig. 13). The follicular cells become cuboidal. The follicular cells above the group of nurse cells migrate posteriorly and gather over the oocyte chamber. Concomitantly their number is decreased above the group of nurse cells, which stretches further to cover the increased area. The yolk accumulation from one-fourth to one-half of the total volume of the egg chamber is observed in stage 9 , and the oocyte nucleus is closer to the posterior nurse cells (Fig. 15). The follicular cells surrounding the nurse cells change from cuboidal to a thin squamous layer, while those surrounding the oocyte appear tall and columnar. The anterior peripheral columnar follicle cells 

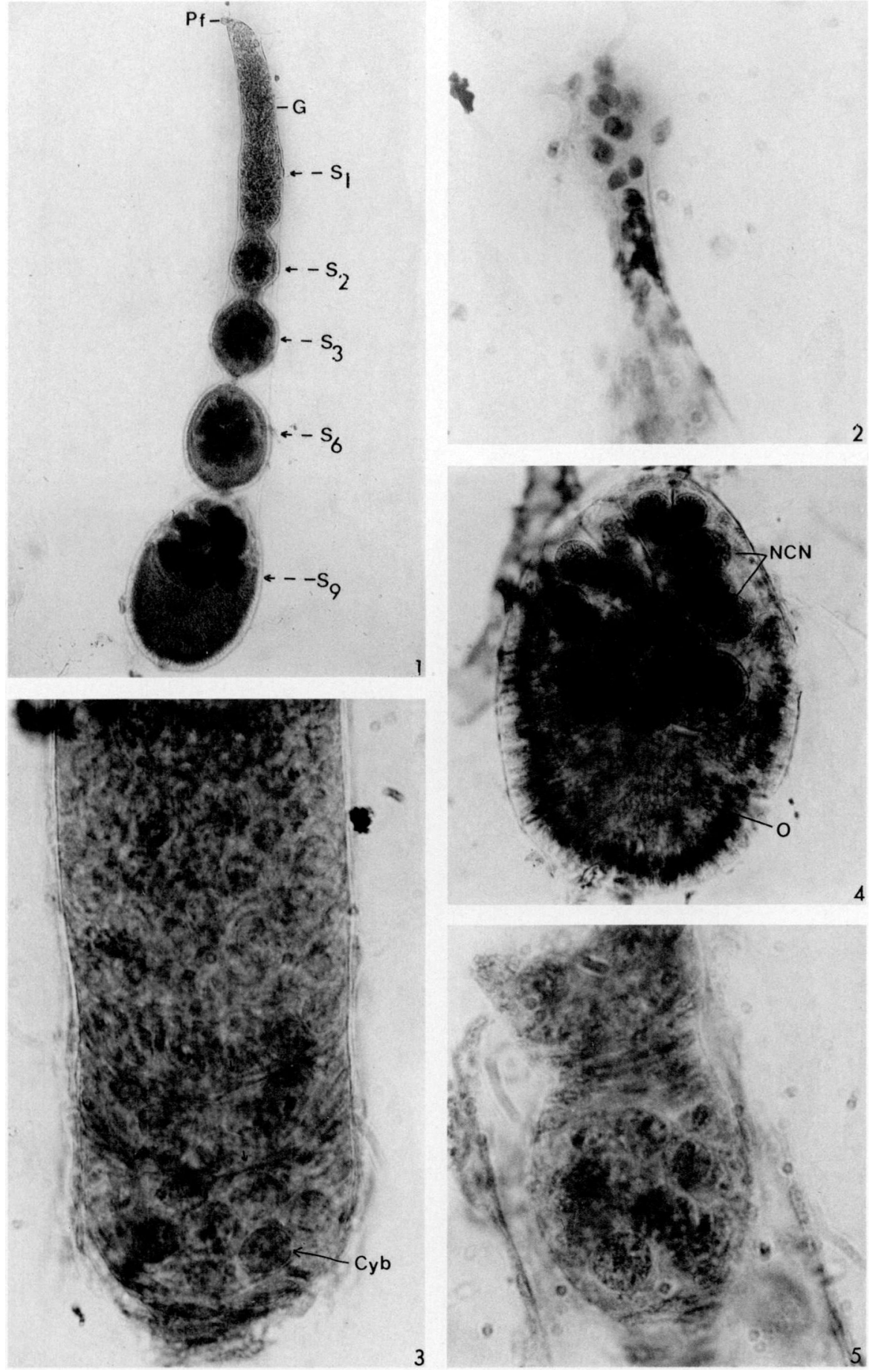

Figs. 1-5. (1) Single ovarian tubule showing 9 successive stages. Pf, polar filament; G, germarium; S, stage. (2) Mitotically active germ cells at the apex of the germarium. (3) Cystoblasts are in a single follicular membrane at posterior part of germarium and oogonial cells are in the other part of the germarium. Arrow denotes faint line of separation. Cyb, cystoblasts. (4) Thirty two cystoblasts in an egg chamber. O, oocyte; NCN, nurse cell nuclei. (5) Circular first egg chamber just separated from the germarium. 

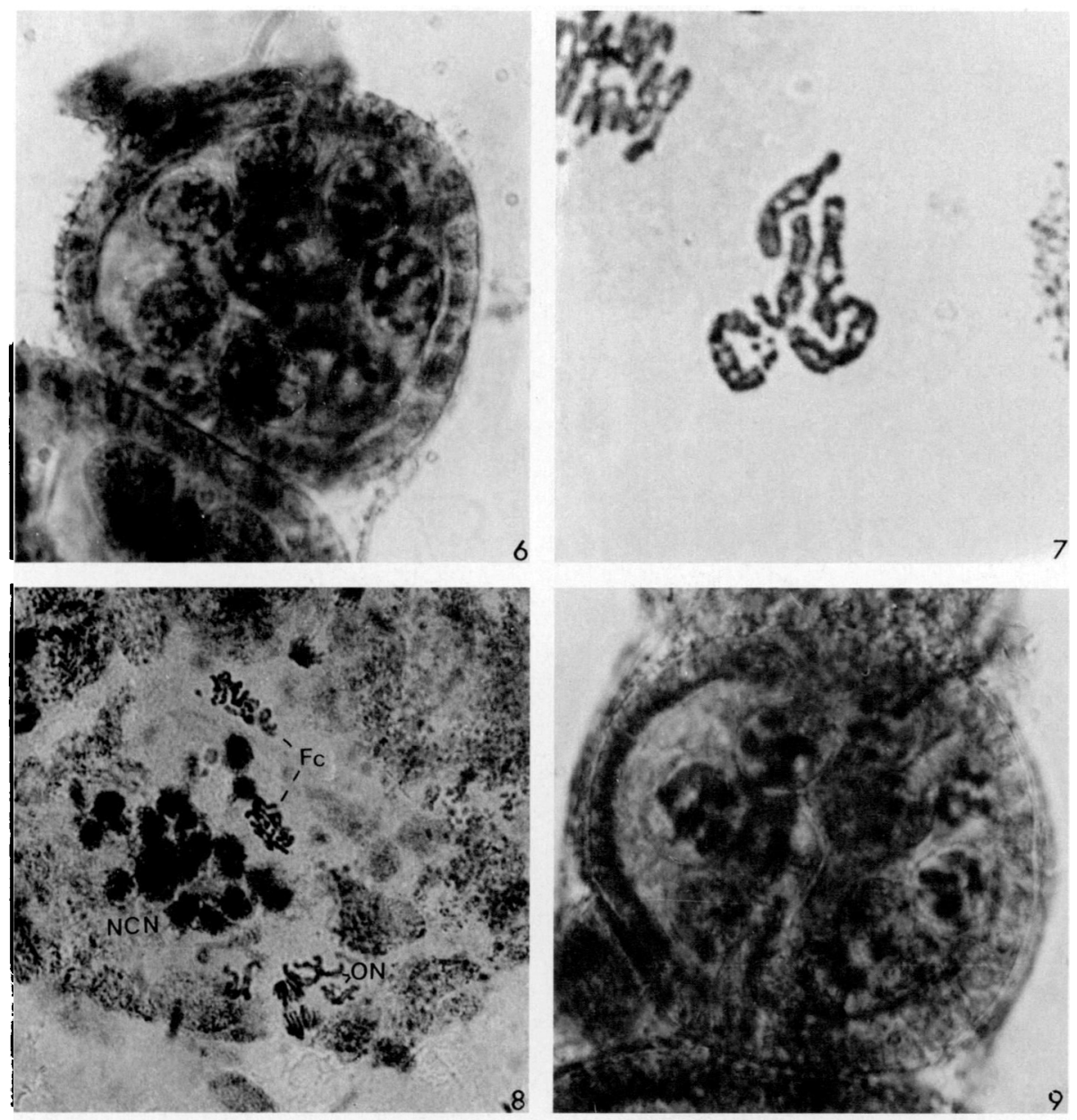

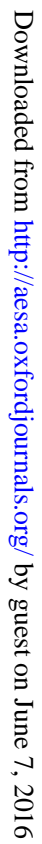
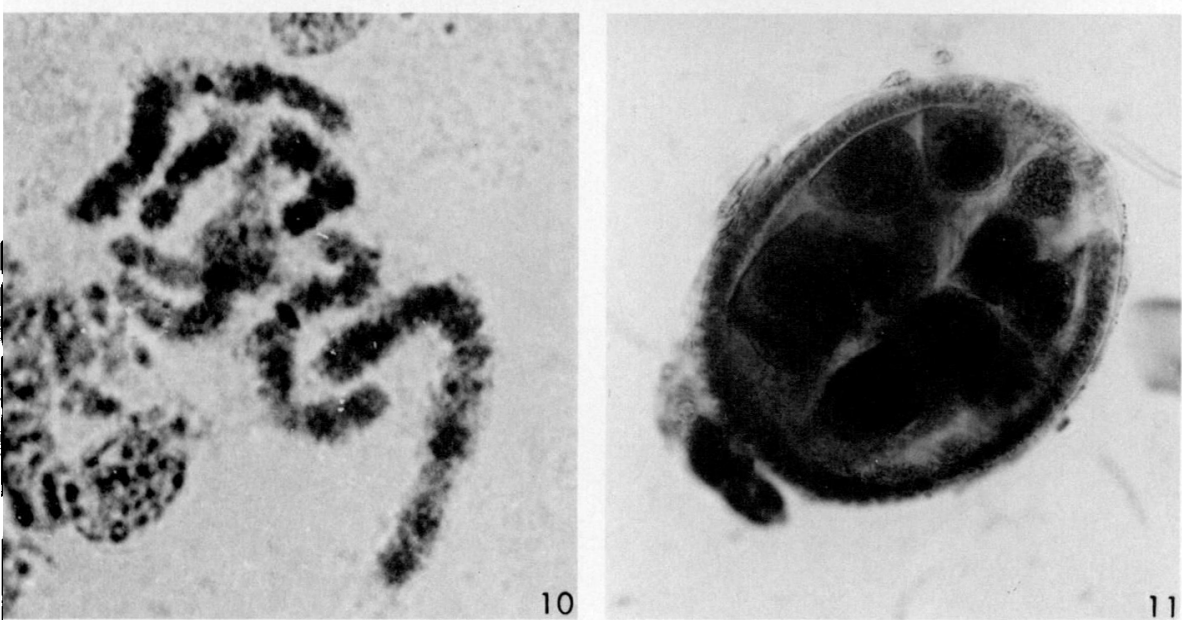

Figs. 6-11 (6) Early endomitotic chromosomes in nurse cell nucleus. (7) Pachytene stage of oocyte nucleus. (8) Egg chamber showing polytene chromosomes in nurse cell nuclei (NCN) and metaphase and anaphase stages in follicular cells $(\mathrm{Fc})$ and phacytene stage in oocyte nucleus $(\mathrm{ON})$. (9) Polytene chromosomes in nurse cell nuclei of an egg chamber. (10) Stranded primary polytene chromosomes. (11) Oval egg chamber changed from circular shape. 

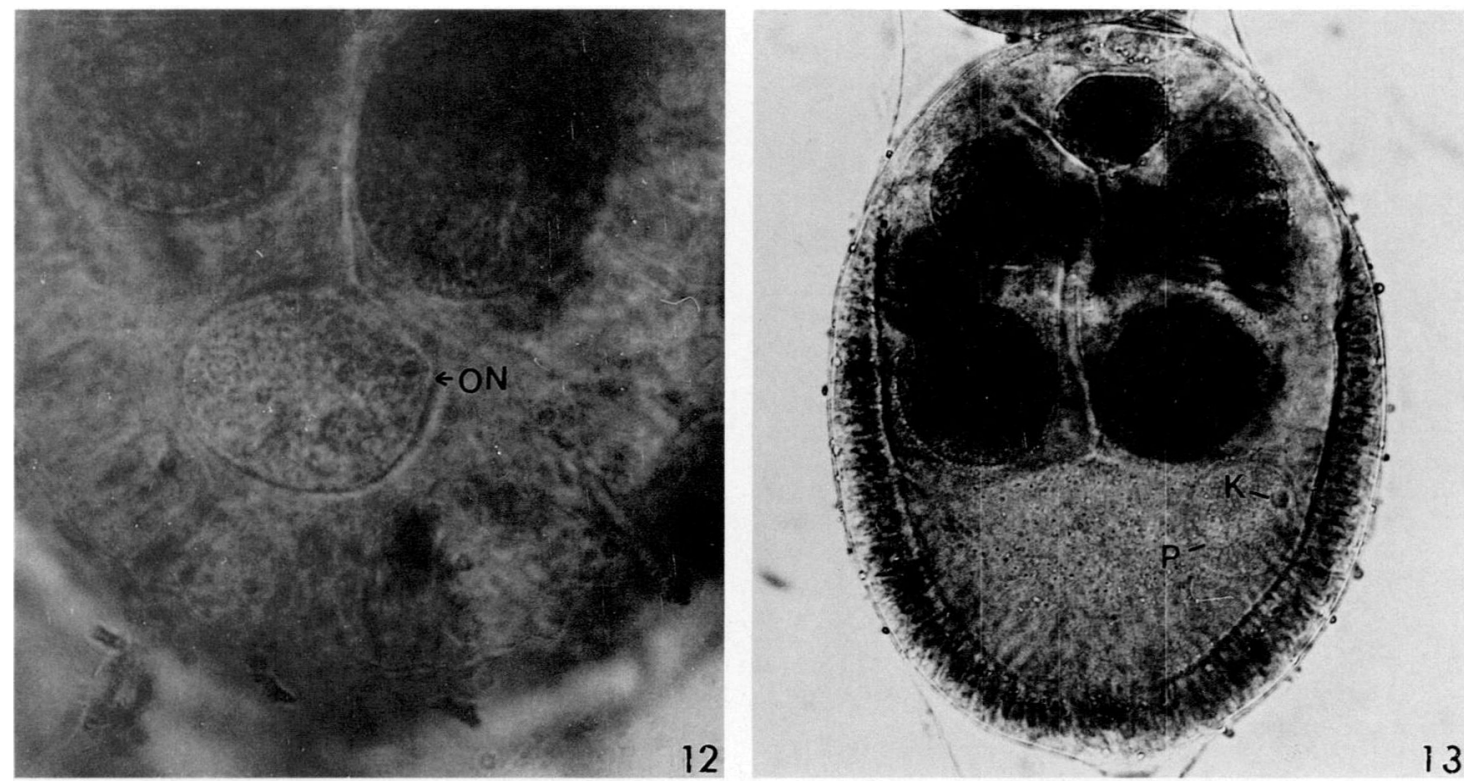

Figs. 12 and 13. (12) Arrow denotes the oocyte nucleus (ON) in the egg chamber. (13) Arrow indicates the karyosome $(\mathrm{K})$ and plasmosome $(\mathrm{P})$. The yolk occupies one-fourth total volume of the egg chamber.

begin a centrifugal migration and lie between the nurse cells and the oocyte (Fig. 15). Further, as and when the yolk accumulation increases in the ooplasm, the nurse cells are pushed anteriorly. During stage 10, the yolk accumulation increases from one-half to nearly three-fourths of the volume, and the oocyte grows much faster at the expense of the nurse cells (Figs. 14 and 16). The nurse cells reach a maximal growth of $40,532.46 \mu^{3}$ with the chromatin material distributed evenly. The maximal ploidy at this stage is estimated as $1024 \mathrm{n}$. The follicle cells in contact with the oocyte secrete a vitelline membrane around the oocyte, except at the region of the micropyle and at the junction of four ring canals.

Table 1. The NCN, the oocyte nucleus and the eggchamber volume correlated with the stages of oogenesis in E. sorbillans

\begin{tabular}{rrrrrr}
\hline \hline & \multirow{2}{*}{$\begin{array}{c}\text { NCN } \\
\text { Stages }\end{array}$} & $\begin{array}{c}\text { Oocyte } \\
\text { nucleus }\end{array}$ & \multicolumn{2}{c}{ Egg chamber } \\
\cline { 5 - 6 } \cline { 5 - 6 } & $\begin{array}{c}\text { Volume, } \\
\mu \mathrm{m}^{3}\end{array}$ & $\begin{array}{c}\text { Volume, } \\
\mu \mathrm{m}^{3}\end{array}$ & $\begin{array}{c}\text { Length, } \\
\mu \mathrm{m}\end{array}$ & \multicolumn{1}{c}{$\begin{array}{c}\text { Volume, } \\
\mu \mathrm{m}^{3}\end{array}$} \\
\hline 1 & 261.50 & 321.68 & 42.55 & $44,832.19$ \\
2 & $2,103.52$ & $2,324.43$ & 52.90 & $68,802.29$ \\
3 & $2,894.76$ & $2,206.39$ & 62.73 & $129,297.86$ \\
4 & $3,425.23$ & $2,206.39$ & 87.40 & $327,965.55$ \\
5 & $3,746.34$ & $2,206.39$ & 106.57 & $584,757.90$ \\
6 & $9,450.63$ & $2,573.43$ & 112.73 & $588,263.50$ \\
7 & $11,351.25$ & $4,446.89$ & 126.50 & $980,734.88$ \\
8 & $18,086.89$ & $9,583.13$ & 175.95 & $2,254,385.90$ \\
9 & $30,841.79$ & - & 250.55 & $4,243,614.00$ \\
10 & $40,532.46$ & - & 353.36 & $7,723,863.10$ \\
11 & $10,309.28$ & - & 416.87 & $10,152,890.00$ \\
12 & $4,906.56$ & - & 442.10 & $13,793,650.00$ \\
13 & 804.57 & - & 486.28 & $14,255,131.00$ \\
14 & - & - & 618.67 & $22,671,272.00$ \\
\hline
\end{tabular}

At stage 11, the nurse cells stop growing and shrink drastically, but the oocyte continues to grow (Figs. 14 and 17; Table 1). The follicular cells which lay between the nurse cells and the oocyte during stages $9-10$, now begin to secrete endochorion (Fig. 18), whereas the follicular cells over the oocyte become flattened. During stage 12, the nurse cells appear as a small cap over the anterior end of the egg chamber, because of the continued growth of the oocyte and the shrinkage of the nurse cells. They latter start to degenerate; their nuclei become pycnotic as their cytoplasmic content flows into the oocyte (Figs. 18 and 19). In stage 13, the oocyte reaches its maximal growth and there will be no further yolk accumulation. Only the rudiments of nurse cells are found at the anterior end of the developing oocyte (Fig. 19). Formation of the exochorion is seen between the epithelial layer and the oocyte at this stage and is completed with the follicular cells becoming flattened until they are sloughed off at stage 14 (Fig. 20). During stage 14 , the chorion appears as an amorphous layer of varying degrees of thickness. When the follicular cells begin to secrete chorion, about 27 anterodorsal and 10 posterodorsal follicular cells become modified and develop into aeropyles, which do not participate in chorion formation. The follicular cells around the anterior aeropyles form an oval operculum (Manjunatha \& Puttaraju 1993). This operculum is joined to the chorion by a faint line of sealing bar. The posterior aeropyles do not have an operculum. The follicular cells near the ring canal develop as a cup-shaped micropylar apparatus without secreting the cho- 


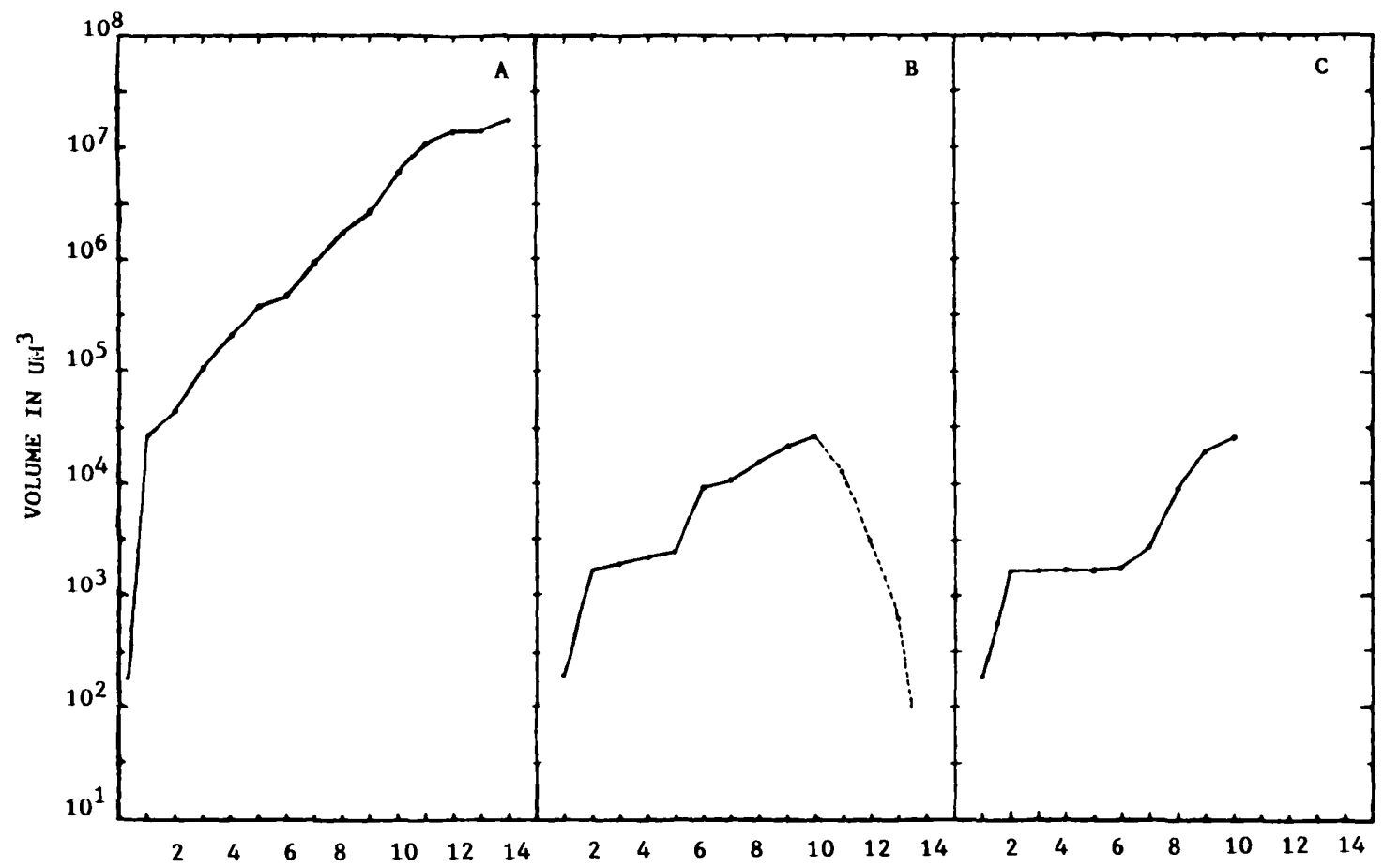

Fig. 14. Growth curve of the egg chamber (a), the nurse cell nuclei (b), and the oocyte nucleus (c), as a function of the egg developmental stages.

rion. Formation of egg membrane and hatching pleat are complete at the end of stage 14 (Fig. $21)$. By this time egg volume is $22,671,272 \mu \mathrm{m}^{3}$ and its length is $618.671 \mu \mathrm{m}$. Now the egg is ready to be deposited. Before oviposition, the egg chamber is covered with the rudiments of the squamous layer of follicular cells. During oviposition, the squamous layer is left within the body and is resorbed by the insect.

During subsequent ovarian cycles, the development of the secondary egg chamber can usually be related to that of the primary egg chamber and the tertiary egg chamber to the secondary. Thus, when the primary egg chamber is in stage 4 , the secondary egg chamber is separated from the germarium in stage 2, and stage 3 occurs when the first egg chamber reaches stage 6 . In the meantime, the tertiary egg chamber at the end of stage 1 becomes separated from the germarium (Fig. 1). The tertiary egg chamber reaches stage 3 when the secondary egg chamber is at stage 6 and the primary egg chamber is at stage 9 . Stages $4-6$ of tertiary and stages 7-9 of secondary egg chamber occur when the first egg chamber is in stages 10-12. When the tertiary egg chamber reaches stages 7-8, the second reaches stages $10-11$, and the primary developing oocyte is fully matured and ready for deposition. If primary egg chambers cannot deposit because a suitable host is not available, the secondary and tertiary egg chambers also reach the deposition stage. When a suitable host is avail- able all the developed eggs are laid almost at the same time. If these eggs are not deposited, further maturation of the remaining egg chambers does not occur. Under laboratory conditions when the host, $B$. mori, is not available, the $E$. sorbillans die after 6-7 d along with its four fully matured, five developing oocytes, and one germarium containing groups of oogonia and cystocytes.

\section{Discussion}

Some cytological changes occurring during oogenesis of Exorista sorbillans are similar to those in Musca domestica (Goodman et al. 1968) and Drosophila melanogaster (King et al. 1956). However, in $E$. sorbillans at the mitotically active phase (stages $1-3$ ), about 20 mitotically active germ cells are found at the apex of the germarium, compared with " 50 or so" in D. melanogaster.

Koch \& King (1966) and Koch et al. (1967) have described in $D$. melanogaster that during the stationary growth phase, the cystocytes are too small to undergo mitosis. Therefore, one of them differentiates into an oocyte and other 15 become nurse cells. This also occurs in E. sorbillans; each oogonial cell occasionally undergoes one more division because of nonoperation of the regulatory mechanism to form one oocyte and 31 nurse cells which are smaller than their successive progenitor nurse cells as in 16 cell stage 

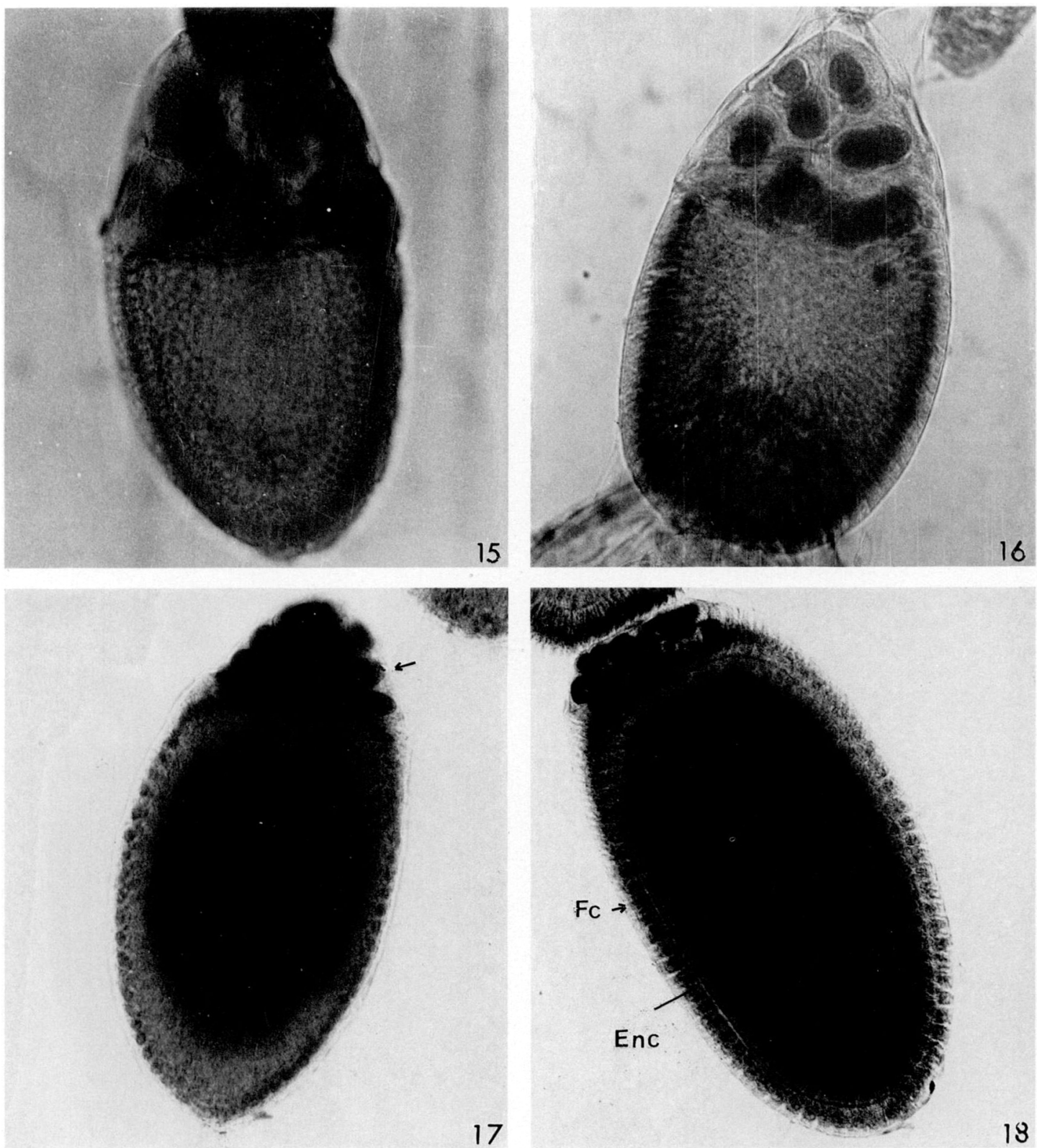

Figs. 15-18. (15) Follicular cells migrated in centrifugal direction and seperates the oocyte from nurse cells chamber. Yolk occupies one-half the volume of the egg chamber. (16) Yolk occupying three-fourths of the volume of the egg chamber. (17) Arrow shows the shrunken nurse cell nuclei. (18) Arrow indicates the formation of endochorion (Enc) and follicular cells ( $\mathrm{fc}$ ).

(Fig. 4). This feature, although rare, must be important to the development of the oocyte, perhaps to synthesize some important and particular protein.

The meiotic events in the E. sorbillans oocyte are quite similar to those of Lucilia cuprina (Beattie \& Cheney 1979) and C. hominivorax (LaChance \& Bruns 1963a). The process of oocyte development in $E$. sorbillans is similar to that of D. melanogaster (King et al. 1956) and in M. domestica (Goodman et al. 1968).
Our study demonstrates the role of NCN in the development of the follicle. The NCN in E. sorbillans exhibit endomitosis at the end of stage 1 , and continues to stage 10. During stages 1-10, the NCN grow exponentially as in $M$. domestica (Goodman et al. 1968) and D. melanogaster (Cummings \& King 1969) but differ in size and degree of endomitosis. At stage 3, nonbanded polytene chromosomes appear; this also occurs in D. melanogaster (Painter \& Reindrop 1939, Hsu \& Hausen 1953, King et al. 1956), C. eryth- 

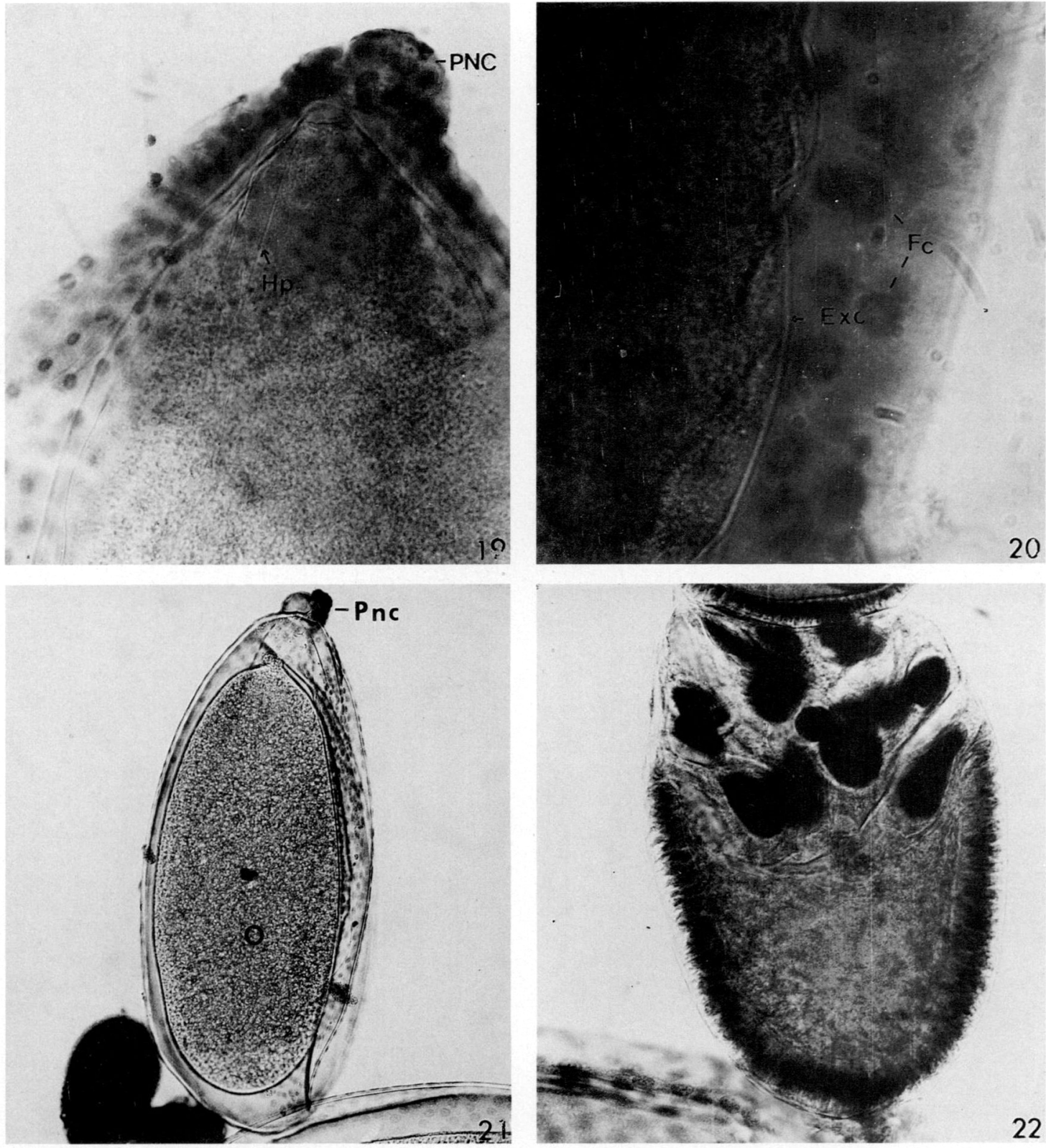

Figs. 19-22. (19) A 'cap' of pycnotic nurse cells (PNC) at the anterior end of egg chamber. Arrow shows the formation of hatching pleat $(\mathrm{Hp})$. (20) The formation of exochorion (Exc) lying between the follicular cells (Fc) and oocyte. (21) Fully developed oocyte (o) Pnc, pycnotic nurse cells. (22) Deformed egg chamber.

rocephala and C. vicina (Bier 1957), and in $L$. cuprina (Beattie \& Cheney 1979) in the first few endomitotic cycles.

The polytene nature disappears in NCN of $E$. sorbillans between stages 4 and 5 at $64 n-128 n$ ploidy. In Drosophila, Calliphora, and Lucilia, (Beattie \& Cheney 1979) they disintegrate after $32 \mathrm{n}$ ploidy. Thus, the appearance and disappearance of the polytene condition seems to be correlated with the particular level of ploidy; what regulates this phenomenon remains enigmatic. At stage 6 the volume of NCN in E. sorbillans suddenly doubles because of replication of chromosomes, which reach a ploidy of $256 \mathrm{n}$ and $160 \mathrm{C}$ DNA content (Table 2; Fig. 14). This has been observed in $D$. melanogaster by Jacob \& Sirlin (1959), who state that the volume of NCN is related to the number of endomitotic replication cycles that have been completed, and correlates fairly well with DNA content. During this time, perhaps a large portion of the chromosomes making up the complete genome including rDNA was replicated for transcription of RNA through DNA amplification (Telfer 1975). The volume of 
Table 2. Mean DNA content and ploidy estimated from the volume of the NCN of E. sorbillans

\begin{tabular}{cccc}
\hline \hline Stages & Volume, $\mu \mathrm{m}^{3}$ & Ploidy $(n)$ & DNA content \\
\hline 1 & 261 & 4 & 4.4 \\
2 & 2,104 & 32 & 35.6 \\
3 & 2,895 & 64 & 49.0 \\
5 & 5,248 & 128 & 88.85 \\
6 & 9,451 & 256 & 160.0 \\
8 & 18,086 & 512 & 268.6 \\
10 & 40,532 & 1024 & 535.5 \\
\hline
\end{tabular}

NCN in $E$. sorbillans gradually increases, attaining $1,024 \mathrm{n}$ ploidy at stage 10 , and having $535.5 \mathrm{C}$ DNA content. From this we infer that the real synthetic activity in the NCN occurs after the disintegration and disappearance of polytene chromosomes, as evidenced by the continuous increase in the size of the NCN until stage 10. However, the disintegration of polytene chromosomes that occurred in E. sorbillans has no effect on the synthetic activity of nurse cells, as has been recorded in other insects by King et al. (1956), Bier (1957), Jacob \& Sirlin (1959), LaChance \& Crystal (1963b), Goodman et al. (1968), LaChance \& Leverich (1968), Cummings \& King (1969), Beattie \& Cheney (1979), and Trepte (1979).

After stage 10, the NCN in E. sorbillans undergo a transition phase during which the accumulated synthesized nucleoproteins are transferred to the oocyte through cellular connections or the ring canal (Gutzeit \& Koppa 1982, Gutzeit 1986, Carcupino et al. 1992). Therefore, the NCN decrease in size and remain pycnotic, which is evident at the end of stage 14 . Such a feature was seen in D. melanogaster (Cummings \& King 1969) and M. domestica (Goodman et al. 1968, Trepte 1979).

While these events are occurring, several changes take place in the egg chamber. During stage 4, vitellogenesis begins, and the volume of the egg chamber increases from 2.595 to $34.06 \%$ of the final volume of the egg chamber at the end of stage 10, from the uptake of extraovarian proteins. This occurs earlier in E. sorbillans than in D. melanogaster (between stages 8-10 [King et al. 1956, Cummings \& King 1959]) and M. domestica (between stages 8-10 [Goodman et al. 1968]). At stage 10, the follicular cells migrate from the surface of the NCN complex and surround the oocyte. Later the follicular cells secrete the vitelline membrane, thus blocking the uptake of extraovarian protein. After stage 10, the volume of the oocyte again increases by the transfer of the nucleoproteins from the NCN, which brings the volume of the matured oocyte to $136,652.75$ times that of the oogonium. In $D$. melanogaster (King et al. 1956) and in M. domestica (Trepte 1979) the size of the follicle is about 100,000 times. This size difference in follicle is accounted for by the amount of yolk accumulated.

The retardation of vitellogenesis leads to the formation of deformed or dead egg chamber with shrunken nurse cells (Fig. 22). In E. sorbillans, this retardation is presumably caused by the effect of one or more environmental factors on the process of endomitosis and synthetic activity during oogenesis. A similar condition has also been reported in Drosophila (King et al. 1956).

\section{Acknowledgment}

The authors are indebted to N. V. Aswathanarayana (Department of Zoology, University of Mysore) for his constructive criticism and valuable suggestions in preparing this article.

\section{References Cited}

Beattie, G.A.C. \& J. Cheney. 1979. Oogenesis in Lucilia cuprina (Wied.) (Diptera: Calliphoridae). 1. Development of nurse cell nuclei, the oocyte nucleus and the follicle cells. Aust. J. Zool. 27: 331347.

Bier, K. 1957. Endomitose and Polytanie in den Nahrzelkernen von Calliphora erythrocephala Meigen. Chromosoma (Berl.) 8: 493-522.

Carcupino, M., C. M. Yin, J. G. Stoffolano, G. Scapigliati \& M. Mazzini. 1992. F-actin distribution in the ovaries of previtellogenic and vitellogenic black blow flies, Phormia regina (Meigen) (Diptera: Calliphoridae). Int. J. Insect Morphol. Embryol. 21: 77-86.

Cummings, M. R. \& R. C. King. 1969. The cytology of the vitellogenic stages of oogenesis in Drosoph ila melonogaster. 1. General staging characteristics. J. Morphol. 128: 427-441.

Goodman, T., P. E. Morrison \& D. M. Davies. 1968. Cytological changes in the developing ovary of the house fly fed milk and other diets. Can. J. Zool. 46: 409-421.

Gutzeit, H. O. 1986. The role of microfilaments in cytoplasmic streaming in Drosophila follicles. J. Cell Sci. 80: 159-169.

Gutzeit, H. O. \& R. Koppa. 1982. Time lapse film analysis of cytoplasmic streaming during late oogenesis of Drosophila. J. Embryol. Exp. Morphol. 67: $101-111$.

Hsu, W. S. \& R. W. Hausen. 1953. The chromosomes in the nurse cells of Drosophila melanogaster. Cytologia (Tokyo) 18: 330-342.

Jacob, J. \& J. I. Sirlin. 1959. Cell function in the ovary of Drosophila. 1. DNA classes in nurse cell nuclei as determined by autoradiography. Chromosoma (Berl.) 10: 210-228.

King, R. C., A. G. Rubinson \& R. F. Smith. 1956. Oogenesis in adult Drosophila melanogaster. Growth 20: 121-157.

Koch, E. A. \& R. C. King. 1966. The origin and early differentiation of the egg chamber of $D$. melanogaster. J. Morphol. 119: 283-304.

Koch, E. A., P. Smith \& R. C. King. 1967. The division differentiation of Drosophila cystocytes. J. Morphol. 121: 55-70. 
LaChance, L. E. \& S. B. Bruns. 1963a. Oogenesis and radiosensitivity in Cochliomyia hominivorax (Diptera: Calliphoridae). Biol. Bull. 124: 63-65.

LaChance, L. E. \& M. M. Crystal. 1963b. The modification of reproduction in insects treated with alkalylating agents. II. Differential sensitivity of meiotic stages to the induction of dominant lethals. Biol. Bull. 125: 250-288.

LaChance, L. E. \& A. P. Leverich. 1968. Cytology of Oogenesis in chemosterilized screw-worm flies, Cochliomyia hominivorax, as related to endomitosis in nurse cells. Ann. Entomol. Soc. Am. 61: 11881197.

Manjunatha, H. B. \& H. P. Puttaraju. 1992a. Ovarian developmental stages of uzi fly, Exorista bombycis (Diptera: Tachinidae), pp. 57-65. In G. P. Channabasavanna, G. Veeranna \& S. B. Dandin [eds.], Recent advances in uzi fly research. KSSDI, Bangalore, India.

Manjunatha, H. B. \& H. P. Puttaraju. 1992b. An analysis of somatic chromosomes in E. bombycis (Diptera: Tachinidae). Cytologia (Tokyo) 57: 321326.

1993. The egg of uzi fly, Exorista sorbillans (Diptera: Tachinidae). Appl. Entomol. Zool. 28: $574-577$.
Painter, T. S. \& E. C. Reindrop. 1939. Endomitosis in the nurse cells of the ovary of Drosophila melanogaster. Chromosoma (Berl.) 1: 276-283.

Patil, G. M. \& R. Govindan. 1984. Internal anatomy of silkworm uzi fly, Exorista sorbillans (Diptera: Tachinidae). Indian J. Seric. 23: 22-31.

Puttaraju, H. P. \& B. N. Chowdaiah. 1984. Cytological studies of the uzi fly, Tricholyga bombycis Beck (Diptera: Tachinidae). Sericologia 24: 519-524.

Siddappaji, C. \& G. P. Channabasavanna. 1990. The Indian uzi fly, Exorista bombycis. A parasitoid of the mulberry silkworm. Indian J. Seric. 29: 119137.

Telfer, W. H. 1975. Development and physiology of the oocyte-nurse cell syncytium. Adv. Insect Physiol. 11: 223-319.

Trepte, H. H. 1979. Rate of follicle growth, change in follicle volume and stages of macromolecular synthesis during ovarian development in Musca domestica. J. Insect Physiol. 25: 191-203.

Whiting, A. R. 1950 . A modification of the SchmuckMetz whole mount technique for chromosome study. Stain Technol. 25: 21-22.

Received for publication 12 May 1993; accepted 8 February 1994. 